Portland State University

PDXScholar

$11-22-2020$

\title{
Fem or Foe?: Non-Communal Women Who Report Sexual Harassment Receive Fewer Career Advancement Opportunities
}

\author{
Katherine A. Werth \\ Portland State University \\ Larry R. Martinez \\ Portland State University \\ Heather A. Firestone \\ Portland State University \\ Timothy A. Carsey \\ Portland State University
}

Follow this and additional works at: https://pdxscholar.library.pdx.edu/honorstheses Let us know how access to this document benefits you.

\section{Recommended Citation}

Werth, Katherine A.; Martinez, Larry R.; Firestone, Heather A.; and Carsey, Timothy A., "Fem or Foe?: NonCommunal Women Who Report Sexual Harassment Receive Fewer Career Advancement Opportunities" (2020). University Honors Theses. Paper 815.

https://doi.org/10.15760/honors.834

This Thesis is brought to you for free and open access. It has been accepted for inclusion in University Honors Theses by an authorized administrator of PDXScholar. Please contact us if we can make this document more accessible: pdxscholar@pdx.edu. 
Running Head: EFFECTS OF REPORTING SEXUAL HARASSMENT

Fem or Foe?: Non-Communal Women Who Report Sexual Harassment Receive Fewer Career Advancement Opportunities

Katherine A. Werth, Heather A. Firestone, Larry R. Martinez, Timothy A. Carsey Portland State University (Psychology Department)

Portland, OR, United States

E-mail: larry.martinez@pdx.edu

he

\begin{abstract}
Sexual harassment is an ever-important topic to organizations, but there is currently a gap in the literature regarding career outcomes for women who report sexual harassment. Past research has discovered that masculine women get harassed more than feminine women and that masculine women have a better chance at career advancement opportunities than feminine women, but there has yet to be any focus on how the gender personality of a sexual harassment survivor relates to organizational success after a sexual harassment report. This study aims to help address this gap by drawing from the stereotype content model (Cuddy, Glick \& Fiske, 2002) and experimentally evaluating the impact of gender personality on career advancement perceptions among hypothetical sexual harassment survivors. A sample of supervisors were asked to read an employee file and then scored the employee based on perceived promotability, hireability, and raise-worthiness. Findings show that women who report harassment receive lower scores of perceived promotability, hireability, and raise-worthiness than women who don't report harassment, and that women described with more traditionally feminine (compared to masculine
\end{abstract}


EFFECTS OF REPORTING SEXUAL HARASSMENT

or neutral) personalities are protected from these effects because they are perceived as being particularly warm.

Keywords: sexual harassment, gender harassment, career advancement, genderpersonality

Fem or Foe?: Non-Communal Women Who Report Sexual Harassment Receive Fewer Advancement Opportunities 
EFFECTS OF REPORTING SEXUAL HARASSMENT

"I thought that by saying no and explaining my reasons my employer would abandon his social suggestions. However, to my regret, in the following few weeks, he continued to ask me out on several occasions... I was aware, however, that telling at any point in my career could adversely affect my future career."

- Anita Hill

Whether women report the harassment they've been subjected to has long been a multifaceted and complex internal debate. In the quote above, lawyer and academic Anita Hill expresses concerns that are reflective of the worries women have in all kinds of workplaces. When they've been the targets of harassment, will filing a formal report harm their career advancement opportunities?

The Equal Employment Opportunity Commission released a report in 2016 which examined the prevalence of experiencing and reporting harassment in the workplace. The rates of sexual harassment were found to vary depending on how the survey items were posed; when asked explicitly if they've experienced sexual harassment in the workplace, approximately $25 \%$ of women stated that they had (Feldblum \& Lipnic, 2016). When the survey provided examples of sexual harassment and asked if women had experienced these specific actions, the rate rose to around $50 \%$ of women; when surveys asked participants via convenience sampling, $75 \%$ of women reported experiencing sexual harassment in the workplace (Feldblum \& Lipnic, 2016). Approximately $60 \%$ of women report having been subject to some form of gender harassment (Feldblum \& Lipnic, 2016). These rates suggest that harassment is a fairly common occurrence for women at work, but only six to $13 \%$ of individuals who experience harassment file a formal report (Feldblum \& Lipnic, 2016), suggesting major concerns about the effects of reporting. 
EFFECTS OF REPORTING SEXUAL HARASSMENT

While women have become increasingly vocal about the common occurrence of sexual harassment in the recent past, this report shows that between 1996 and 2016 there have been no significant changes in the frequency of sexual harassment formally reported by women (Feldblum \& Lipnic, 2016). Women instead have utilized social media via the \#MeToo movement to expose the prevalence of harassment and express their fear of consequences due to reporting. With the majority of harassment going unreported, there must be barriers to taking the formal step of reporting within an organization. Past studies have found that $75 \%$ of employees who reported their harassment faced some sort of retaliation (Feldblum \& Lipnic, 2016), but there is a lack of research investigating the potential career outcomes that incur post-reporting. In this study, workplace outcomes (e.g., promotability, hireability, and raise-worthiness) are examined for women who report sexual and gender harassment as a function of reporter gender personality type.

\section{The Negative Impact of Reporting Sexual Harassment}

Women who stray from traditional notions of femininity and identify as feminists are the women who are most likely to both confront the perpetrator and report harassment to Human Resources because these individuals are likely to be more assertive than women who tend to fit gender ideals (Adams-Roy, 1994; Adams-Roy \& Barling, 1998; Brooks \& Perot, 1991). Past research has looked at the effects of reporting harassment to HR on the survivor. Results have shown that official reporting leads to lower job satisfaction, psychological distress, poorer health, increased mental health problems, lowered perceptions of procedural justice, and lowered organizational commitment (Adams-Roy \& Barling, 1998; Bergman, Langhout, Palmiere, Cortina, \& Fitzgerald, 2002). Although current literature has a clear understanding of these psychological and health-related outcomes of reporting sexual harassment, there is a lack of 
EFFECTS OF REPORTING SEXUAL HARASSMENT

research evaluating the different career outcomes for women who file a formal report. This is especially problematic considering that women are incredibly underrepresented in maledominated fields and positions of power, with less than $5 \%$ of Fortune 500 companies having female CEOs (PEW Research Center, 2018; Heilman, 1997; National Science Foundation, 2011; Wessel et al., 2014). The women who are the most likely to be harassed (hyper masculine and gender role deviating) tend to also have traits that would put them at an advantage for obtaining positions in male-dominated industries and leadership roles within them (Berdahl, 2007; Brooks \& Perot, 1991; Wessel et al., 2014), which speaks to how men may use harassment as a tool to combat the threat they perceive against the organizational power they hold. Because of the negative intrapersonal effects of harassment reporting and the common backlash women recieve post-reporting, we predict that reporting harassment will have a negative impact on women's career advancement opportunities.

H1: Women who report any form of harassment will receive fewer favorable career advancement outcomes ((a)promotability, (b) hireability, (c) raise-worthiness) than women who don't report harassment.

$\underline{\text { Motivations for Sexual and Gender Harassment }}$

The research evaluating which women are most vulnerable to workplace harassment is situated between several theories regarding the motivations of a harasser. The common conception of sexual harassment is that the harassing behavior is a product of sexual desire toward the survivor (Franke, 1997; Gutek, 1985; MacKinnon, 1979; Schultz, 1998). Sexual harassment has often been stereotyped by the idea of an attractive secretary being taken advantage of by her boss. Contrary to this image, there are now large amounts of evidence showing that the majority of sexual harassment women face in the workplace stems from 
EFFECTS OF REPORTING SEXUAL HARASSMENT

perceptions of their gender performativity and associated level of threat they have against the harasser's power in a patriarchal system, resulting in masculine women recieving more harassment via gender harassment (Berdahl, 2007; Fitzgerald et al., 1988; Fitzgerald, Drasgow, Hulin, Gelfand, \& Magley, 1997; Fitzgerald et al., 1999; Franke, 1997; Schultz, 1998; U.S. Merit Systems Protection Board, 1981, 1988, 1995; Waldo, Berdahl, \& Fitzgerald, 1998). Gender harassment can be categorized as "a form of hostile environment harassment that appears to be motivated by hostility toward individuals who violate gender ideals rather than by desire for those who meet them" (Berdahl, 2007). Because gender harassment isn't characterized by unwanted sexual advances, many people disregard its existence, as the common workplace harassment narrative regarding women includes unwanted sexual overtures. Despite this, it remains a real and detrimental phenomenon, as gender-harassed women have been found to show significant decrements in their professional and psychological well-being (Leskinen, Cortina \& Kabat, 2011). Because sexual harassment often follows a widely-held script, there are times in which reporting may be seen as justified; gender harassment, however, is an issue that isn't as universally regarded as a problem within organizations, leading to predictably worse backlash upon reporting.

H2: Women who report gender harassment will receive fewer favorable career advancement outcomes ((a) promotability, (b) hireability, (c) raise-worthiness) than women who report sexual harassment.

\section{Gender Roles: Prescription and Deviance}

West and Zimmerman (1987) proposed that gender is performative such that women are expected to engage in feminine behaviors and demeanors, including communal traits such as being a nurturing "team-player" and taking on supportive roles (see also Wessel et al., 2014). Masculine women deviate gender roles by exhibiting more agentic qualities including 
EFFECTS OF REPORTING SEXUAL HARASSMENT

assertiveness and independence (Wessel et al., 2014; West \& Zimmerman, 1987). According to role congruity theory, individuals who fail to align with gender-based stereotypes are punished for their deviance (Eagly \& Karau, 2002). Further, Connell’s gender order theory and explanation of hegemonic masculinity demonstrates how men maintain the dominant position in society by subordinating women who express masculine traits (Connell, 1987; Connell, 2005). Taken together, this research clearly demonstrates that sexual harassment is often primarily motivated by a desire to punish gender-role-deviating women rather than by sexual desire. Previous research has looked at the specific gender personalities of women who are most likely to receive sexual harassment, finding that masculine women indeed are the most likely targets (Berdahl, 2007). Further, masculine women are more likely than feminine women to receive a male-dominated position, such as a supervisory position (Wessel, Hagiwara, Ryan, \& Kermond, 2014); while past research provides a clear understanding of these concepts separately, it remains unclear how these phenomena interact. Because agentic women deviate from traditional notions of femininity more than communal women do, we predict that their outcomes will be worse after reporting harassment compared to communal or neutral women. Further, because gender harassment is more closely related to gender deviance than sexual harassment is, we expect that agentic women in this condition will recieve the worst outcomes of any group.

H3: Agentic women who report any harassment will receive fewer favorable career advancement outcomes ((a) promotability, (b) hireability, (c) raise-worthiness) than communal or neutral women who report any harassment.

H4: Agentic women who report gender harassment will receive fewer favorable career advancement outcomes ((a) promotability, (b) hireability, (c) raise-worthiness) than every other group. 
EFFECTS OF REPORTING SEXUAL HARASSMENT

\section{$\underline{\text { Stereotype Content Model as the Framework for Harassment Likelihood }}$}

The stereotype content model (SCM) provides the mechanism that may explain why masculine women can be expected to be punished more frequently than their feminine counterparts (Fiske, Cuddy, Glicke $\& \mathrm{Xu}, 2002$ ). The SCM posits that people are perceived on the dimensions of warmth and competence, which determines how others evaluate them. The results of SCM studies demonstrate a clustering of attitudes towards different groups into four quadrants linked to an emotional concomitant of the perceiver, which then can be used to predict behaviors enacted towards particular groups (Fiske et al., 2002; Fiske, Cuddy, \& Glick, 2007). Findings have shown that typical women (e.g., communal/feminine) are perceived to have high warmth and low competence, eliciting pity and passive facilitation, but career women (e.g. agentic/masculine) are perceived to be low in warmth and high in competence, eliciting envy and active harm (Eckes, 2002; Fiske, Cuddy \& Glick, 2007).

These delineations can help explain the predictable behavior of managers towards women who report sexual harassment, depending on their gender personalities which may elicit different evaluations of warmth and competence. Because perceptions of warmth influence active actions and perceptions of competence influence passive actions, we predict that agentic women will receive active harm in the form of worsened career advancement opportunities, and that perceptions of warmth will mediate this interaction such that communal women are protected from negative outcomes.

H5: Perceptions of warmth will mediate the relationship between reporting harassment and career advancement outcomes ((a) promotability, (b) hireability, (c) raiseworthiness). 
EFFECTS OF REPORTING SEXUAL HARASSMENT

\section{Methods}

\section{Participants}

Participants were 511 employees with management experience (262 women) that were recruited via MTurk. Eighty percent worked full-time. Fifty-nine percent identified as White/Non-Hispanic, 21\% as Asian, 6\% as African American or Black, 5\% as Indian or South Asian, 5\% as Hispanic or Lantinx, 2\% as Biracial or Multiracial, and $1 \%$ or less as Native American, Alaskan Native, Native Hawaiian, Pacific Islander, Middle Eastern, or other. Average age was 36.98 years $(S D=11.39)$.

\section{Design and Procedure}

This experiment involved a 3 (sexual harassment, gender harassment, or control) x 3 (communal, agentic, or neutral gender personality) between-participant design. We screened participants for supervisory experience using Smith, Sabat, Martinez, Weaver, and Xu's (2015) procedure. Participants then reviewed an employee file that contained a recent performance review and an incident report that had been filed to HR.

The personality manipulation was achieved by using agentic, communal, or neutral descriptive language in the performance review. Specifically, the woman described was a highperforming accountant in all scenarios. The harassment manipulation was achieved using descriptions of sexual harassment (the woman's buttock was grabbed), gender harassment (the woman's work capabilities were undermined based on gender), or no harassment (a coffee-spill accident; see the Appendix for the manipulation verbiage). In all scenarios of harassment, no evidence was found, and the perpetrator received minimal punishment. This echoed the fears that many women claimed having when reporting sexual harassment (Feldblum \& Lipnic, 2016). 
EFFECTS OF REPORTING SEXUAL HARASSMENT

Participants then rated the woman's promotability, hireability, raise-worthiness, warmth, and competence.

\section{Measures}

Promotability. We measured perceived promotability using the seven-item Promotability Ratings Measure from Harris, Kacmar, and Carlson (2006) with unipolar Likert scales $(1=$ strongly disagree, $7=$ strongly agree; $\alpha=.91)$. Sample items include "If I had to select an employee for a promotion, this employee would be a likely candidate?" and "I believe that this employee has high potential."

Hireability. We measured perceived hireability using the four-item Hireability Scale from Madera, Hebl, and Martin (2009) with unipolar Likert scales (1 = not at all, 9 = very much; $\alpha=.93)$. Sample items include "How likely would you be willing to hire this employee?" and "To what extent is this a "top-notch" employee?"

Raise Worthiness. We measured likelihood to grant a raise using a two-item scale developed for this study with unipolar Likert scales $(1=$ strongly disagree, $7=$ strongly agree; $\alpha$ $=.89$ ). Sample items include "I would give this employee a raise if they asked for one" and "This employee should receive a raise.”

Warmth and Competence. We measured warmth and competence using the four- and five-item scales, respectively, developed by Fiske, Cuddy, Glick, and Xu (2002) with unipolar Likert scales $\left(1=\right.$ not at all, $5=$ extremely; $\left.\alpha_{\text {Warmth }}=.89, \alpha_{\text {Competence }}=.84\right)$.

\section{Results}

We used Hayes’ (2013) PROCESS Macro (Model 7) with Harassment entered as the IV, Personality entered as the moderator, Warmth and Competence entered as parallel mediators, and Promotability, Hireability, and Raise-Worthiness entered as DVs in three separate models. 
EFFECTS OF REPORTING SEXUAL HARASSMENT

Across DVs, these analyses revealed significant mediation effects for Warmth in each condition except when the target experienced sexual harassment and expressed a communal personality. In all cases, Competence was not a significant mediator. Follow-up ANCOVAs with Warmth as the DV and Competence as a covariate revealed significant main effects such that targets in both the gender $(M=3.71, S D=0.89)$ and sexual $(M=3.91, S D=0.76)$ harassment conditions were rated as being less Warm than the control condition $(M=4.18, S D=0.70), F(2,501)=22.79, p$ $<.001, \eta^{2}=0.08$. In addition, targets depicted with agentic $(M=3.89, S D=0.76)$ and neutral $(M$ $=3.79, S D=0.86)$ personalities were rated less warm that those depicted as communal $(M=$ 4.11, $S D=0.78)$ personalities, $F(2,501)=24.65, p<.001, \eta^{2}=0.09$ (see Figure 1). There were no significant interactions. These results confirm the assumption that ratings along the SCM influence women's career outcomes, suggesting that communal-acting women who report sexual harassment are protected from the negative reactions that other types of women and types of harassment elicit because they are perceived as being particularly warm.

\section{Discussion}

This study provides the first examination of career outcomes for women who report sexual harassment and produces a viable explanation for why some women's careers may lack advancement if they have filed a formal report. The results of this study show that agentic and neutral women who report harassment receive fewer career advancement opportunities than women who don't report harassment, but that communal women don't face these same disadvantages. These findings partially support $\mathrm{H} 1$, and the differential outcomes for communal women compared to the other personalities can be explained by their higher perceptions of warmth, supporting H5. Communal women who reported sexual harassment had significantly higher ratings of warmth than agentic or neutral women, and this served as a mediating, 
EFFECTS OF REPORTING SEXUAL HARASSMENT

protective factor for them against negative career outcomes post-reporting. Support was also found for H6, as perceptions of competence did not mediate the relationship between reporting and outcomes. For the agentic and neutral women, their reporting of harassment had a significant negative impact on perceptions of their promotability, hireability, and raise-worthiness, and these effects were greatest among the agentic women, supporting $\mathrm{H} 3$ and H4. Among all groups, reporting gender harassment led to worse career outcomes than reporting sexual harassment, supporting $\mathrm{H} 2$.

These findings demonstrate the impact of adhering to gender roles in the workplace; presumably, the communal women's alignment with traditional feminine traits served to characterize them within the "damsel in distress" archetype which allows for sexual harassment reporting to be seen as justified since it fulfills the common sexual harassment script. Without perceptions of high warmth protecting them, agentic and neutral women face very different consequences. Importantly, these differences emerged solely as a function of survivor personality, as the harassment they received was standardized. Overall, these results suggest that women are at a disadvantage for obtaining career opportunities after reporting harassment, but that these disadvantages differ among women depending on their gender personalities, being worse for those who demonstrate more masculine traits and are more likely to experience gender harassment.

This study exhibits that there are different stereotypes associated with women who are masculine and feminine (Fiske \& Stevens, 1996), and these stereotypes come into play when it is known that the woman has reported harassment in the workplace. This study also provides more evidence for role congruity theory (Eagly \& Karau, 2002) and gender order theory (Connell, 1987) by demonstrating the punishments faced by women who fail to align with traditional 
EFFECTS OF REPORTING SEXUAL HARASSMENT

notions of femininity in the workplace. Stereotype content research is also built upon by this study; the model is further validated through the demonstration of warmth being a mediator for the predictable outcomes of the various women who were evaluated.

This research adds to the body of existing work concerning gender personality, as it provides another example of the ways people with gender personalities that do not match what is societally expected can be stigmatized, thus contributing to differential career outcomes. The current study also adds to sexual harassment literature by widening the collective knowledge of the consequences of sexual harassment reporting, expanding beyond the intrapersonal effects and beginning a formal discussion of how women's careers are impacted by the instance(s) of reporting. These findings shed light onto career advancement as a whole; women are incredibly underrepresented in higher level organizational positions, and the data from this study can help explain a portion of this phenomenon as the women who are most likely to receive higher positions are also the most likely to report harassment (Adams-Roy, 1994; Adams-Roy \& Barling, 1998; Brooks \& Perot, 1991; Wessel et al., 2014).

This study provides helpful insight to both supervisors and employees. Supervisors can become aware of their possible biases regarding women who report sexual harassment and can consciously work to stop these biases from influencing career advancement opportunities. They also can be encouraged to evaluate the bases on which they determine promotability, hireability, and raise-worthiness in general, avoiding reliance on gender stereotypes. Sexual harassment trainings and policies can be amended to include best practices for once harassment has occurred; while education regarding the identification and prevention of sexual harassment is necessary, the findings of this research can inform the organizational reaction to a report. This knowledge is also helpful to working women, as they can use this information to make better 
EFFECTS OF REPORTING SEXUAL HARASSMENT

informed decision(s) regarding reporting and their evaluation of the organizational reaction and possible consequences. While women should never be discouraged from reporting, they should have the knowledge of possible outcomes to be able to make the right decision for themselves. Lastly, men and non-binary individuals can use this information to further educate themselves on the realms in which they can express their allyship.

\section{Limitations and Future Directions}

Like all experiments, this study has multiple limitations. Firstly, managers are not always aware of sexual harassment reports, so these results are not fully generalizable. Recruiting participants via MTurk also makes this work less generalizable, as MTurk workers have been found to be not fully representative of the general population in regard to race, age, education level, religiosity, and employment status (Goodman, Cryder, \& Cheema, 2013; Paolacci et al., 2014), though we don't think these factors make a significant difference on our data given the nature of the experiment, and because the reliability of MTurk data has not been found to be significantly different than data collected by other means (Buhrmester at al., 2011).

Using only one method is another limitation; with multiple methods, particularly qualitative ones, the findings would be further solidified and there would be a much deeper understanding of the actual experiences of harassment reporters and their perceptions of organizational reactions and potential consequences. Qualitative interviews with women who have reported sexual/gender harassment would provide this awareness. Women who have been sexually harassed but made the decision to not make a formal report could also be interviewed, explaining their concerns and holdbacks, which would broaden the collective understanding of women's experiences in the workplace and their perceptions around the impact of reporting. Interviews with supervisors about their process of evaluation and promotion would shed light on 
EFFECTS OF REPORTING SEXUAL HARASSMENT

their perspective of this organizational practice, potentially revealing conscious and/or unconscious biases.

This study also fails to examine how the race, sexual orientation, and ability status of the woman reporting could change her career outcomes post-reporting. According to intersectionality theory (Crenshaw, 1989), it is likely that people who hold different combinations of these identities would be perceived and treated differently, as they are constantly evaluated with all of these factors in mind, whether it be consciously or subconsciously. Assumedly, women with multiple marginalized identities would face harsher consequences than those who don't, but formal studies would have to be conducted to confirm this and determine the degree to which discrepancies exist.

Lastly, studies should be conducted regarding the experiences of men and non-binary individuals who report sexual/gender harassment. While stereotypes around sexual harassment lead to the assumption that women are the only people to be sexually harassed in the workplace, this isn't true, but there isn't much literature comparing how the rates and results of reporting may differ between genders. Evaluating these differences would provide more understanding as to how gender and gender expression influence reactions to sexual harassment reporting, highlighting the particular issues faced by non-communal women. 
EFFECTS OF REPORTING SEXUAL HARASSMENT

Adams-Roy, J. E. (1994). Will she or won't she? Factors influencing the likelihood that women will report or confront sexual harassment (Doctoral Dissertation). Retrieved from ProQuest. MM95424.

Adams-Roy, J. \& Barling, J. (1998). Predicting the decision to report or confront sexual harassment. Journal of Organizational Behaviour, 19, 329-336.

Berdahl, J. L. (2007). The sexual harassment of uppity women. Journal of Applied Psychology, $92,425-437$.

Berdahl, J. L., Magley, V. J., \& Waldo, C. R. (1996). The sexual harassment of men: Exploring the concept with theory and data. Psychology of Women Quarterly, 20, 527-547.

Bergman, M. E., Langhout, R. D., Palmieri, P. A., Cortina, L. M., \& Fitzgerald, L. F. (2002). The (un)reasonableness of reporting: antecedents and consequences of reporting sexual harassment. Journal of Applied Psychology, 87, 230-242.

Brooks, L. \& Perot, A. R. (1991). Reporting sexual harassment, exploring a predictive model. Psychology of Women Quarterly, 15, 31-47.

Buhrmester, M., Kwang, T., \& Gosling, S. D. (2011). Amazon’s Mechanical Turk: A new source of inexpensive, yet high-quality data? Perspectives on Psychological Science, 6(1), 3-5.

Burgess, D., \& Borgida, E. (1999). Who women are, who women should be: Descriptive and prescriptive gender stereotyping in sex discrimination. Psychology, Public Policy, and the

Law, 5, 665-692.

Connell, R. W. (1987). Gender and power: society, the person and sexual politics. Sydney Boston: Allen \& Unwin.

Connell, R. W. (2005). Masculinities (2nd ed.). Berkeley, California: University of California 
EFFECTS OF REPORTING SEXUAL HARASSMENT

Press.

Crenshaw, Kimberle. (1989). Demarginalizing the Intersection of Race and Sex: A Black Feminist Critique of Antidiscrimination Doctrine, Feminist Theory and Antiracist Policies." University of Chicago Legal Forum no. 1 139-167.

Cuddy, A. J. C., Fiske, S. T., \& Glick, P. (2007). The BIAS map: Behaviors from intergroup affect and stereotypes. Journal of Personality and Social Psychology, 92(4), 631-648.

Dall'Ara, E., \& Maass, A. (1999). Studying sexual harassment in the laboratory: Are egalitarian women at higher risk? Sex Roles, 41, 681-704.

Eagly, A. H., \& Karau, S. J. (2002). Role congruity theory of prejudice toward female leaders. Psychological Review, 109(3), 573-598.

Eckes, T. (2002). Paternalistic and envious gender stereotypes: Testing predictions from the stereotype content model. Sex Roles 47, 99-114.

Feldblum, C. R., \& Lipnic, V. A. (2016). Select task force on the study of harassment in the workplace. Washington, DC. Retrieved from https://www.eeoc.gov/eeoc/task_force/harassment/report.cfm

Fiske, S. T., Cuddy, A. J. C., Glick, P., \& Xu, J. (2002). A model of (often mixed) stereotype content: Competence and warmth respectively follow from perceived status and competition. Journal of Personality and Social Psychology, 82, 878-902.

Fiske, S. T., Cuddy, A. J. C., Glick, P., \& Xu, J. (2002). Competence and warmth scales. Retrieved from PsycTESTS.

Fitzgerald, L. F., Drasgow, F., Hulin, C. L., Gelfand, M. J., \& Magley, V. J. (1997). Antecedents and consequences of sexual harassment in organizations: A test of an integrated model. Journal of Applied Psychology, 82, 578-589. 
EFFECTS OF REPORTING SEXUAL HARASSMENT

Fitzgerald, L. F., Magley, V. J., Drasgow, F., \& Waldo, C. R. (1999). Measuring sexual harassment in the military: The Sexual Experiences Questionnaire (SEQ-DoD). Military Psychology Special Issue: Sexual Harassment, 11, 243-263.

Fitzgerald, L. F., Shullman, S. L., Bailey, N., Richards, M., Swecker, J., Gold, A., et al. (1988). The incidence and dimensions of sexual harassment in academia and the workplace. Journal of Vocational Behavior, 32, 152-175.

Franke, K. M. (1997). What's wrong with sexual harassment? Stanford Law Review, 49, $691-772$.

Goodman, J. K., Cryder, C. E., \& Cheema, A. (2013). Data collection in a flat world: The strengths and weaknesses of Mechanical Turk samples. Journal of Behavioral Decision Making, 26, 213-224.

Gutek, B. A. (1985). Sex and the workplace: The impact of sexual behavior and harassment on women, men, and organizations. San Francisco: Jossey-Bass.

Leskinen, E.A., Cortina, L.M., \& Kabat, D.B. (2011). Law and Human Behavior, 35(1), 22-39.

Harris, K. J., Kacmar, K. M., \& Carlson, D. S. (2006). Promotability ratings measure. Retrieved from PsycTESTS.

Heilman, M. E. (1997). Sex discrimination and the affirmative action remedy: The role of sex stereotypes. Journal of Business Ethics, 16, 877-889.

Maass, A., Cadinu, M., Guarnieri, G., \& Grasselli, A. (2003). Sexual harassment under social identity threat: The computer harassment paradigm. Journal of Personality and Social Psychology, 85, 853-870.

MacKinnon, C. A. (1979). Sexual harassment of working women. New Haven, CT: Yale University Press. 
EFFECTS OF REPORTING SEXUAL HARASSMENT

Madera, J. M., Hebl, M. R., \& Martin, R. C. (2009). Hireability scale. Retrieved from PsycTESTS.

Mateo, A., \& Menza, K. (2017). The Results of a 1976 Survey of Women about Sexual Harassment at Work Remain Virtually Unchanged in 2017. Redbook (March 27, 2017), www.redbookmag.com/life/money-career/a49220/sexual-harassment-in-the-workplace.

Meijs, M., Ratliff, K. A., \& Lammers, J. (2017). Perceptions of feminist beliefs influence ratings of warmth and competence. Group Processes \& Intergroup Relations, 22(2), 253-270.

National Science Foundation, Division of Science Resources Statistics. (2011). Women, minorities, and persons with disabilities in science and engineering: 2011 (Report NSF 11-309). Retrieved from http://www.nsf.gov/statistics/wmpd/

Paolacci, G., \& Chandler, J. (2014). Inside the Turk: Understanding Mechanical Turk as a participant pool. Current Directions in Psychological Science, 23(3), 184-188.

Rospenda K. M., Richman J. A., \& Shannon C. A. (2009). Prevalence and mental health correlates of harassment and discrimination in the workplace: Results from a national study. Journal of interpersonal violence, 24(5), 819-843.

Rudman, L. A. \& Glick, P. (2002). Prescriptive Gender Stereotypes and Backlash Toward Agentic Women. Journal of Social Issues. 57(4), 743-762. 10.1111/0022-4537.00239

Schultz, V. (1998). Reconceptualizing sexual harassment. Yale Law Journal, 107, 1683-1796.

Smith, N. A., Sabat, I. E., Martinez, L. R., Weaver, K., \& Xu, S. (2015). A convenient solution: Using MTurk to sample from hard-to-reach populations. Industrial and Organizational Psychology: Perspectives on Science and Practice, 8, 220-228.

The Data on Women Leaders. (2018, September 13). Retrieved May 24, 2019, from https://www.pewsocialtrends.org/fact-sheet/the-data-on-women-leaders/ 


\section{EFFECTS OF REPORTING SEXUAL HARASSMENT}

U.S. Merit Systems Protection Board. (1981). Sexual harassment in the federal workplace: Is it a problem? Washington DC: U.S. Government Printing Office.

U.S. Merit Systems Protection Board. (1988). Sexual harassment in the federal government: An update. Washington DC: U.S. Government Printing Office.

U.S. Merit Systems Protection Board. (1995). Sexual harassment in the federal workplace: Trends, progress, continuing challenges. Washington, DC: U.S. Government Printing Office.

Waldo, C. R., Berdahl, J. L., \& Fitzgerald, L. F. (1998). Are men sexually harassed? If so, by whom? Law and Human Behavior, 22, 59-79.

Wessel, J. L., Hagiwara, N., Ryan, A. M., \& Kermond, C. Y. M. (2014). Should Women Applicants “Man Up” for Traditionally Masculine Fields?: Effectiveness of Two Verbal Identity; Management Strategies. Psychology of Women Quarterly (39), 243-255.

West, C., \& Zimmerman, D. (1987). Doing Gender. Gender \& Society, 1(2), 125-151.

\section{Appendix}

Control Report 
EFFECTS OF REPORTING SEXUAL HARASSMENT

\section{Workplace Incident Report}

REPORTED BY: Tracy Jones

TITLE / ROLE: Accounting Supervisor
DATE OF REPORT: $12 / 14 / 18$

INCIDENT NO.: 1104

\section{WORKPLACE INCIDENT INFORMATION}

DATE OF INCIDENT: $\quad 12 / 14 / 18$

TIME OF INCIDENT: Around 3:10

NAME OF PERSON DEMONSTRATING PROHIBITED BEHAVIOR: Michael Porter

NAME OF VICTIM: Tracy Jones

LOCATION: Break Room

SPECIFIC AREA OF LOCATION: By the coffee pot

ADDITIONAL

PERSON(S) INVOLVED: none

WITNESSES:

INCIDENT DESCRIPTION INCLUDING ANY EVENTS LEADING TO OR IMMEDIATELY FOLLOWING THE INCIDENT:

Michael and I were discussing a new restaurant in town when he accidentally spilled coffee on me, which caused a slight burn on my right arm. He helped me run it under cold water, put burn cream on it, and clean up the mess. We both returned to work with no issues and no lasting harm done.

NAMES OF SUPERVISORY STAFF INVOLVED ALONG WITH THEIR RESPONSE TO THE INCIDENT:

Dave Thompson:

Both parties were spoken to and this was clearly an accident. Neither feel any further action is necessary and the report has been filed in compliance with company policy.

RESULTING ACTION EXECUTED, PLANNED, OR RECOMMENDED:

Employees were checked in on and the proper report has been filed for liability issues.

REPORTING
STAFF NAME: Tracy Jones

SUPERVISOR

NAME: Dave Thompson
REPORTING STAFF

SIGNATURE:

DATE: $\quad 12 / 14 / 18$

SUPERVISOR

SIGNATURE:
DATE: $12 / 14 / 18$

Gender Harassment Report 
EFFECTS OF REPORTING SEXUAL HARASSMENT

\section{Workplace Incident Report}

REPORTED BY: Tracy Jones

TITLE / ROLE: Accounting Specialist
DATE OF REPORT: $12 / 14 / 18$

INCIDENT NO.: 1104

\section{WORKPLACE INCIDENT INFORMATION}

DATE OF INCIDENT: $\quad 12 / 13 / 18$

TIME OF INCIDENT: Around 3:10

NAME OF PERSON DEMONSTRATING PROHIBITED BEHAVIOR: Michael Porter

NAME OF TARGET: Tracy Jones

LOCATION: Break Room

SPECIFIC AREA OF LOCATION: By the coffee pot

ADDITIONAL

PERSON(S) INVOLVED:

WITNESSES: none

INCIDENT DESCRIPTION INCLUDING ANY EVENTS LEADING TO OR IMMEDIATELY FOLLOWING THE INCIDENT:

Michael and I were in the break room discussing a new restaurant in town when he told me he thought I "would clean up nice" and squeezed my buttock. I told him to stop, he said he was just joking around and I was overreacting. He left the break room and I eventually went back to my desk. This isn't the first time he has tried to allude to wanting to go out or sleep with me.

NAMES OF SUPERVISORY STAFF INVOLVED ALONG WITH THEIR RESPONSE TO THE INCIDENT:

Dave Thompson:

We do not condone harassment of any kind in our office, but I have spoken to Michael and he denies these events. With no witnesses or proof, it is hard to say what really happened.

RESULTING ACTION EXECUTED, PLANNED, OR RECOMMENDED:

Michael was spoken to and will receive extra sexual harassment training.

REPORTING

STAFF NAME:

Tracy Jones

SUPERVISOR

NAME: Dave Thompson
REPORTING STAFF

SIGNATURE:

DATE: $\quad 12 / 14 / 18$

SUPERVISOR

SIGNATURE:
DATE: $\quad 12 / 15 / 18$

\section{Sexual Harassment Report}


EFFECTS OF REPORTING SEXUAL HARASSMENT

\section{Workplace Incident Report}

\author{
REPORTED BY: Tracy Jones \\ TITLE / ROLE: Accounting Specialist
}

DATE OF REPORT: $12 / 14 / 18$

INCIDENT NO.: $\quad 1104$

WORKPLACE INCIDENT INFORMATION

DATE OF INCIDENT: $\quad 12 / 13 / 18$

TIME OF INCIDENT: Around 3:10

NAME OF PERSON DEMONSTRATING PROHIBITED BEHAVIOR:

Michael Porter

NAME OF TARGET: Tracy Jones

LOCATION: Break Room

SPECIFIC AREA OF LOCATION: By the coffee pot

ADDITIONAL

PERSON(S) INVOLVED: none

WITNESSES: none

INCIDENT DESCRIPTION INCLUDING ANY EVENTS LEADING TO OR IMMEDIATELY FOLLOWING THE INCIDENT:

Michael and I were in the break room discussing an upcoming quarterly report when he told me "I can do the hard math for you, dear" and patted me on the back. I told him to not belittle my abilities, he said he was just joking around and I was overreacting. He left the break room and I eventually went back to my desk. This isn't the first time my work abilities have been questioned by him.

NAMES OF SUPERVISORY STAFF INVOLVED ALONG WITH THEIR RESPONSE TO THE INCIDENT:

Dave Thompson:

We do not condone incivility of any kind in our office, but I have spoken to Michael and denies the events. With no witnesses or proof, it is hard to say what really happened.

RESULTING ACTION EXECUTED, PLANNED, OR RECOMMENDED:

Michael was spoken to and will be watched for future poor behavior.

REPORTING

STAFF NAME:

Tracy Jones

SUPERVISOR

NAME: Dave Thompson
REPORTING STAFF

SIGNATURE:

DATE: $12 / 14 / 18$

SUPERVISOR

SIGNATURE:

DATE: $\quad 12 / 15 / 18$

Neutral Gender Personality Performance Review 
EFFECTS OF REPORTING SEXUAL HARASSMENT

\begin{tabular}{|c|c|c|c|}
\hline SUPERVISOR NAME & Dave Thompson & DEPARTMENT & Accounting \\
\hline REVIEW PERIOD & $6 / 17-6 / 18$ & DATE OF REVIEW & $7 / 17 / 18$ \\
\hline
\end{tabular}

Tracy is a very good and talented employee. She is capable and regularly finishes projects ahead of schedule. Tracy is very level-headed, so when she runs into a problem, she isn't afraid to ask for help. Tracy is very reliable and quality is always a guarantee.

ACHIEVEMENT OF GOALS

Tracy has achieved multiple goals for the department. She is reliable and will pursue a goal until it is completed. Tracy has been important in the timely processing of expense reports, and an asset in the making of quarterly reports for the quarterly review. The main goals that have been completed the past year are timely completion of quarterly and expense reports and successful presentations to the district manager.

\section{EXAMPLES OF EXCEPTIONAL PERFORMANCE}

Tracy is a very skilled accountant. Her attention to detall allows her to find many accounting errors that would go unseen. She will seek out extra work. Her most notable advancement has been developing a more streamlined process for the reporting of expense reports, making it much easier to approve and reimburse employees. Tracy has also added to office morale by organizing an office trivia team.

\section{SUGGESTED AREAS OF IMPROVEMENT}

Tracy might benefit from being more open to criticism.

Communal Gender Personality Performance Review 
EFFECTS OF REPORTING SEXUAL HARASSMENT

\begin{tabular}{|c|c|c|c|}
\hline \multicolumn{4}{|c|}{ EMPLOYEE INFO: Iracy Jones, Accounfing Specialist } \\
\hline SUPERVISOR NAME & Dave Thompson & DEPARTMENT & Accounting \\
\hline REVIEW PERIOD & $6 / 17-6 / 18$ & DATE OF REVIEW & $7 / 17 / 18$ \\
\hline
\end{tabular}

Tracy is a very friendly and cooperative employee. She is helpful and regularly finishes projects ahead of schedule. Tracy is very team-oriented, so when she runs into a problem, she isn't afraid to ask for help. Tracy is very collaborative in work and quality is always a guarantee.

ACHIEVEMENT OF GOALS

Tracy was pivotal to the achievement of multiple goals for the department. She is a team player and will work towards a goal until it is completed. Tracy has been very supportive in the timely processing of expense reports, and an incredibly collaborative asset in the making of quarterly reports for the quarterly review. The main goals that have been completed the past year are timely completion of quarterly and expense reports and successful presentations to the district manager.

\section{EXAMPLES OF EXCEPTIONAL PERFORMANCE}

Tracy is a very helpful accountant. Her attention to detail enables her to point out many accounting errors that would go unseen. She is helpful and will seek out extra work. Her most notable accomplishment has been developing a more streamlined process for the reporting of expense reports, making it much easier to approve and reimburse employees. Tracy has also added to office morcle by organizing regular birthday celebrations for coworkers.

\section{SUGGESTED AREAS OF IMPROVEMENT}

Tracy might benefit from being more independent from the team.

Agentic Gender Personality Performance Review 
EFFECTS OF REPORTING SEXUAL HARASSMENT

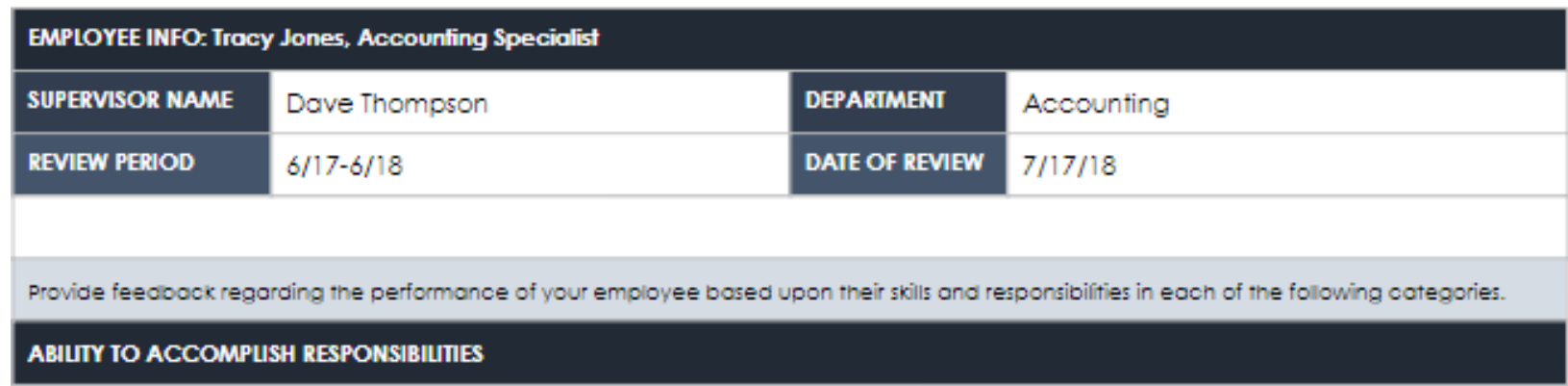

Tracy is a very able and determined employee. She is ambitious and regularly finishes projects ahead of schedule. Tracy is very assertive, so when she runs into a problem, she isn't afraid to ask for help. Tracy is very influential and quality is always a guarantee.

\section{ACHIEVEMENT OF GOALS}

Tracy has independently achieved multiple goals for the department. She is a go-getter and will pursue a goal until it is completed. Tracy has been very influential in the timely processing of expense reports, and an incredibly competent asset in the making of quarterly reports for the quarterly review. The main goals that have been completed the past year are timely completion of quarterly and expense reports and successful presentations to the district manager.

\section{EXAMPLES OF EXCEPTIONAL PERFORMANCE}

Tracy is a very talented accountant. She is proactive which enables her to find many accounting errors that would go unseen. She is self-reliant and will seek out extra work. Her most notable accomplishment has been developing a more streamlined process for the reporting of expense reports, making it much easier to approve and reimburse employees. Tracy has also added to office morale by organizing an office softball team.

\section{SUGGESTED AREAS OF IMPROVEMENT}

Tracy might benefit from being more involved with the team. 